\title{
Graduate Teaching Assistants Views of Their Own Teaching Practice Com- petence
}

Mrs. Rachel Louis Kajfez, Virginia Tech

Rachel Louis Kajfez is a Ph.D. candidate in the Department of Engineering Education at Virginia Tech. She earned her Bachelor's and Master's degrees in Civil Engineering from The Ohio State University where she specialized in construction. Currently, Rachel is a Dean's Teaching Fellow, is a Departmental Ambassador, and is actively involved in ASEE. Her current research interests include graduate student motivation and identity development.

Dr. Holly M Matusovich, Virginia Tech 


\title{
Graduate Teaching Assistants Views of Their Own Teaching Practice Competence
}

\begin{abstract}
Graduate teaching assistants (GTAs) serve a variety of roles in engineering classrooms including primary instructor, lab supervisor, grader, classroom assistant, and more. Although responsibilities vary, the importance of GTAs to undergraduate students' learning experiences is often quite high as these roles put GTAs in direct and extended contact with students. Therefore, it is important that GTAs be appropriately trained for their classroom roles. Developing and improving such training in meaningful ways requires understanding GTA experiences, in their own words and from their own perspectives. To date, little is known about GTA experiences in engineering from the viewpoint of the GTAs. Even less is known specifically about GTA views on their own ability beliefs, and literature shows that such competence beliefs are particularly important for positive teaching experiences. Therefore, this study intentionally examines the competence beliefs of GTAs involved in first-year engineering programs (FYEPs) with regard to their knowledge and application of teaching practices or pedagogy. For this research, five interviews were conducted and analyzed with GTAs representing five different institutions. Based on the analysis, GTAs report little training specifically on teaching practices from their FYEPs, but they do indicate that training is provided through other venues at the university which helps them improve their teaching.
\end{abstract}

\section{Introduction}

Graduate teaching assistants (GTAs) are a vital component to engineering courses including many first-year engineering programs (FYEPs). FYEPs tend to be large in size, having multiple sections of the same class requiring the use of GTAs whose roles vary across institutions from instructional staff to lab supervisors to graders. ${ }^{1-4}$ Despite the widespread use of GTAs in engineering, especially in FYEPs, little is known about GTA's experiences from the perspective of the GTA. While there are studies that describe and evaluate preparation courses for GTAs, evaluations tend to be short-term (e.g., right after the course) and do not examine the longer-term impacts such as GTAs confidence and ability beliefs with regard to actually using such training. This study begins closing this gap by examining GTAs views on their own teaching practice or pedagogy competence.

\section{Scope of This Work}

This work is part of a larger study aimed at understanding the motivation and identity development of GTAs involved in FYEPs. The larger research study is a multi-phased mixed methods research project that has employed reoccurring journal entry surveys over an academic term, semi-structured interviews, and a nationwide survey. This portion of the project focuses on a subset of the interviews from the larger work and concentrates on the topic of teaching practice or pedagogy competence. Competence beliefs are foundational to both motivation and identity $^{5,6}$ and therefore are the most appropriate place to begin analysis for the larger project. Figure 1 below depicts the larger study in general terms. 


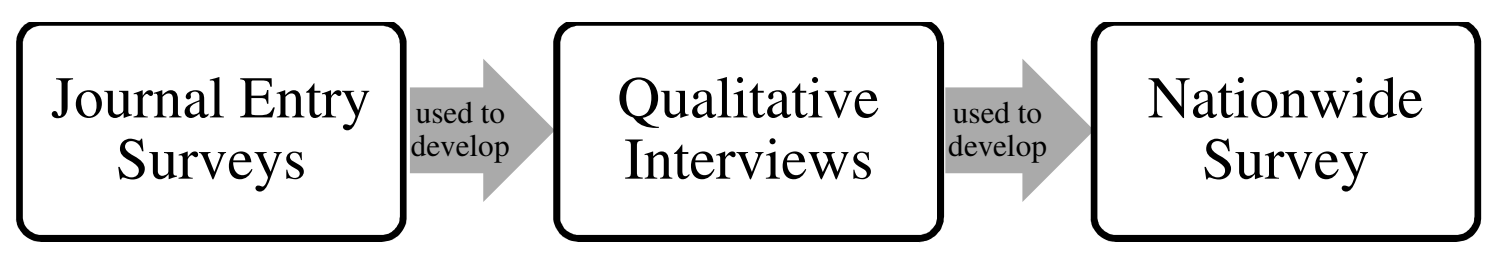

Figure 1: Overall Study Design

The interviews analyzed for this paper come from the qualitative interview phase of the larger study that was developed out of the journal entry surveys and used to develop the nationwide survey. Future manuscripts will detail the methods and findings in the other phases of this work and will examine additional components of the GTA experience.

\section{Situation in Current Literature}

While there is considerable literature on programs created for GTA development, many of the studies are descriptive and often lack either a research component altogether or an evaluation of the long-term impact of the interventions. ${ }^{7-9}$ As Jamieson and Lohmann ${ }^{10}$ have stressed, practice must inform research and research inform practice. Both components are essential to ensure the future establishment of research based training programs geared towards enhancing the specific pedagogical needs of GTAs. This study draws on literature relevant to GTA development from both within and outside of engineering education and particularly focuses on competence beliefs in a research study designed to inform practice.

\section{Literature on GTA Development}

A significant body of literature outside of engineering focuses on how GTAs develop into teachers and more specifically how they learn to teach. ${ }^{11,12}$ Particularly relevant to our research, Nyquist and Sprague ${ }^{11}$ suggest that there are three developmental stages that GTA progress through as they learn to teach: 1) senior learner, 2) colleague-in-training, and 3) junior colleague. Importantly, these stages are situated in a perspective of teaching as a social system such that they address the changing feelings GTAs may have about their students and superiors as they develop. These findings lay the foundation for our work by highlighting the importance of considering how GTAs experience teaching in order to consider the ways to better prepare them for their teaching roles.

Within engineering education, there is also an emerging body of literature on GTA development. This literature tends to focus on describing GTA development programs, ${ }^{7-9,13}$ identifying GTA roles and responsibilities in the classroom, ${ }^{2-4}$ and describing GTA evaluations or assessments based on faculty and student perceptions. ${ }^{14,15}$ Within this body of literature, few studies consider the GTAs' perspective though notable exceptions exist including GTA perspective work by Crede and Borrego, ${ }^{16}$ Goodlad, ${ }^{17}$ and Winters and Matusovich. ${ }^{18}$

By intersecting research from within and outside of our field, our research fills a gap in the current literature as a whole. We use GTAs' perspectives as the main source of data to better understand the GTA development process specifically with regard to how GTAs build teaching practice competence on a personal level. 


\section{Defining Competence}

Competence, as it is discussed in this paper, is a basic need that is a component of SelfDetermination Theory (SDT). SDT is a motivation theory that suggests that people act in ways that lead to satisfaction based of basic psychological needs. ${ }^{5}$ For the purposes of this study, we are concerned with GTAs motivation to teach and their psychological needs as teachers. Within SDT, three psychological needs have emerged as particularly salient including competence, ${ }^{19,20}$ relatedness, ${ }^{21,22}$ and autonomy. ${ }^{23,24}$ Autonomy refers to ownership and control, competence refers to knowledge, and relatedness refers to a sense of connection or belonging. ${ }^{5}$ Ryan and Deci $^{5}$ state that the three components (competence, autonomy, and relatedness) "appear to be essential for facilitating optimal functioning of the natural propensities for growth and integration, as well as for constructive social development and personal well-being" of an individual (p. 68). Each of these components is needed for intrinsic or self-driven motivation which is highly desirable at the core of SDT. Since SDT focuses on understanding individual motivation and development in specific contexts, which for this study will be FYEPs, it is an appropriate framework for this work that examines GTAs' personal perspectives on their teaching practice competence beliefs. For this particular paper, we will only focus on the need of competence because we believe it serves as the foundation for research on the other psychological needs.

It is often said that if you can teach something, you have truly mastered it. This notion of mastery at a fundamental level relates to the SDT component of competence. SDT suggests that people act in ways that satisfy competence needs, and therefore, it is important to understand what competence means in teaching. Various studies have looked at different factors comprising teacher competence with intentions of defining competence. For example, in one study teacher competence included content knowledge, pedagogical knowledge, classroom management knowledge, etc. ${ }^{25}$ In another study, competence referred to an understanding of the subject knowledge, children learning, curriculum, and the educational system. ${ }^{26}$ These studies all suggest that competence is multi-faceted, and we anticipate the same would be true for GTAs in engineering.

Competence has also been studied in literature on teachers and teaching practices with regard to evaluating programs aimed at enhancing teacher competence ${ }^{27}$ and assessing various aspects of teacher competence. ${ }^{28}$ Importantly, past research has shown that through interventions curriculum knowledge can be improved through the implementation of better designed lesson plans ${ }^{27}$ suggesting that competence can be developed. However, research has also shown that assessments of competence should be context specific to ensure they are accurate. ${ }^{28}$ These works are relevant to GTAs in engineering because they support the idea that with increased training GTAs can be successful teachers and that their unique teaching context requires a very specific level or definition of competence.

We have bounded our study to be consistent with current literature by limiting our scope and being context specific. For this analysis, we have chosen to focus on the competence of teaching practices or pedagogy as they relate to teaching within a FYEP. While the literature discussed above points to other areas of GTA competence, we have chosen this piece of competence as a 
starting point for this work scoping our study under the methodological recommendations of Miles and Huberman ${ }^{29}$ to ensure a focused and thorough examination of this interest area.

\section{Literature Summary and Research Questions}

The current body of literature on GTAs includes discussions of the process (stages) of GTA development into teachers or as in engineering education literature, discussions of GTA training programs. Little work exists that studies the GTAs perspective on their experiences in these programs, in their training, and in their teaching. This paper will fill a gap in the literature by exploring the need of competence as it relates to teaching practice or pedagogy knowledge to better understand how GTAs in FYEPs are trained.

Specifically this study will answer the following research questions:

- What training is currently being offered to GTAs to improve their teaching practice competence?

- How to GTAs view their competence including their teaching practice knowledge?

- How, if at all, are GTAs applying what they have learned about teaching practices while teaching?

\section{Methods}

To begin to understand GTAs' views of their teaching practice competence, interviews were conducted with GTAs at a variety of institutions each having common FYEPs. Having a common FYEP means that, all engineering students take the same introductory engineering course(s). Common FYEPs were chosen because they are not discipline specific which provides continuity across institutions and because they tend to focus on common topics such as teamwork, communication, graphing, problem solving, etc.

For this analysis, we draw on five semi-structured interviews, each from a different institution, to provide a broad picture of GTAs' views on teaching competence. While this is a small sample, we believe that the interviews chosen are a strong representation of the experiences of GTAs and therefore our qualitative analysis yields rich, meaningful and impactful results. Before the interviews, the participants were asked to complete a pre-interview survey that asked for basic demographic information such as years of experience, gender, responsibilities, etc. During the interviews, the participants were asked a variety of questions relating to their motivation and identity. Specifically with regard to their competence they were asked about what, if any, training they received, how they learned information necessary for their role, and how comfortable they felt with their level of knowledge related to being a GTA. Interviews were approximately one hour long and were completed over the phone during the Summer 2012 academic term by one researcher. The interviews were audio-recorded and transcribed verbatim for analysis. All research was conducted in accordance with approved human subjects research protocols. 


\section{Participants}

The five participants selected for this study were all GTAs teaching within a common FYEP who volunteered to participate in an interview. The five participants were selected for this analysis from the larger pool of interviews (12 interviews in total still representing five FYEPs) for the larger research project to represent variety in level, masters and PhD students, universities, and engineering disciplines. The basic demographic information for the five participants is shown in Table 1 to provide context. We are using pseudonyms for both the participants and universities to ensure the participants' identities remain confidential and anonymous.

Table 1: Participant Demographics

\begin{tabular}{|c|c|c|c|c|}
\hline Participant & University & Male/Female & Degree & Major \\
\hline Ingrid & University 1 & Female & PhD & Engineering Education \\
\hline Gordon & University 2 & Male & Masters & Civil \\
\hline Corey & University 3 & Male & Masters & Civil \\
\hline Roberto & University 4 & Male & PhD & Civil \\
\hline Maurice & University 5 & Male & Masters & Industrial \\
\hline
\end{tabular}

All five of the universities represented in this study are classified as research institutions. Also in terms of the first-year programs represented, all five of the institutions operate with a twocourse sequence FYEP structure where students take one course in the Fall term and another course within the same program during the Spring term. Finally, all five of these programs employ GTAs as both lab/workshop leaders and graders, and all but University 3 employ them to assist with curriculum development.

\section{Analysis}

A case study approach was used to analyze the results where the case is defined as GTAs teaching within a FYEP. ${ }^{29}$ To begin the analysis, an a priori coding method was used where the interviews were compared to the three basic needs identified in SDT (competence, relatedness, and autonomy). Following the a priori coding, general open coding was used to better understand GTAs experiences through an inductive perspective. For this round of coding, the framework was removed from the analysis to allow the results to naturally emerge. Once the open coding was complete, the framework with the a priori codes was reapplied where the open codes were mapped back to the a priori codes for classification. Both the a priori round of coding and the open coding were conducted with another researcher to ensure inter-rater reliability amongst the codes and to improve code definitions. Once the open coding was complete along with the mapping to a priori codes, the construct of teaching practice competence was revisited to begin to answer the research questions for this study. Future papers will explore the open codes that were developed out of this work as this paper only focuses on the items related to teaching practice competence. 


\section{Results and Discussion}

Based on the analysis described above, we directly answered our research questions. Key findings were observed directly related to the training GTAs receive in FYEPs, their pedagogy competence beliefs, and how they apply teaching practice knowledge in the classroom.

\section{Current Training}

For our sample, we found that teaching practice competence was related to both formal and informal training. What we mean is that it was through conversations on training that participants most often discussed pedagogical topics and views on teaching practices. Subsequently, the open code of "training" was found to provide the most insight regarding teaching practice competence. During the open coding process, "training" was defined as any instance where a GTA discussed learning something necessary for their role in either a formal or informal setting where another person lead or guided the learning. This did not include learning material on their own such as voluntarily sitting in on another GTA's lab or practicing the class material they had to teach on their own time. The "training" code did include both content training and pedagogy training and encompassed both formal and informal training. Table 2 depicts the sub-codes developed out of the "training." It also includes an indication of which participants cited the various types of formal training as a component of their FYEP.

Table 2: Sub-Codes Related to Training

\begin{tabular}{|l|c|c|c|c|c|}
\hline Type of Training & Gordon & Ingrid & Corey & Roberto & Maurice \\
\hline $\begin{array}{l}\text { Onetime Beginning of Year } \\
\text { Training Provided By Group } \\
\text { Outside of the FYEP }\end{array}$ & $\mathrm{X}$ & $\mathrm{X}$ & $\mathrm{X}$ & $\mathrm{X}$ & \\
\hline $\begin{array}{l}\text { Onetime Beginning of Year } \\
\text { Training Provided By the FYEP* }\end{array}$ & $\mathrm{X}$ & $\mathrm{X}$ & & & $\mathrm{X}$ \\
\hline $\begin{array}{l}\text { Informal Training through } \\
\text { Faculty Input }\end{array}$ & $\mathrm{X}$ & $\mathrm{X}$ & $\mathrm{X}$ & & $\mathrm{X}$ \\
\hline $\begin{array}{l}\text { Workshops Throughout } \\
\text { Year/Monthly Discussions }\end{array}$ & $\mathrm{X}$ & $\mathrm{X}$ & $\mathrm{X}$ & $\mathrm{X}$ & $\mathrm{X}$ \\
\hline $\begin{array}{l}\text { Weekly Content } \\
\text { Training/Overview* }\end{array}$ & $\mathrm{X}$ & $\mathrm{X}$ & $\mathrm{X}$ & & \\
\hline Required to Attend Lecture* & $\mathrm{X}$ & & & & \\
\hline Run the Training* & & & & \\
\hline
\end{tabular}

Note: The stared items were included in the coding of training, but were directly related to content knowledge opposed to pedagogy competence. They have been included in this table to demonstrate the various training GTAs receive in general in FYEPs, but are outside of the scope of this manuscript.

The sub-codes above that directly relate to formal teaching practice training and therefore teaching practice competence, opposed to content training, are "onetime beginning of the year training provided by group outside of the FYEP" and "workshops throughout year/monthly discussions." In the five interviews, these were the only two formal instances of teaching 
practice training that could be found to influence teaching practice competence beliefs. In both of these forms of training, the topics discussed by the GTAs related to teaching practices or pedagogy, not just content. For the "onetime training provided by a group outside of the FYEP," the training was usually administered by a teaching and learning center. For the "workshops throughout year/monthly discussions," the training was usually administered by someone in the FYEP. This could have been an experienced GTA or a faculty member. Often the topics discussed in either of these trainings related to managing groups of students, facilitating questions, teaching ethics, and encouraging participation.

Regarding the formal pedagogy training documented in Table 2, Roberto commented that:

"You are supposed to go to these like seminars at the beginning. Uh, when you are in your first year, like the first week, but I don't think they like track your attendance or anything like that... Not everyone goes. Like I went to a couple of them, and they were, basically kind of boring, so we left."

For Roberto, initial training is required, but it did not have a great impact. The required initial training parallels the findings in the follow up to the Boyer Report where it was found that $70 \%$ of research universities provide mandatory initial training for their GTAs. ${ }^{30}$ If other GTAs hold the same reaction to this training as Roberto, it is logical that GTAs do not seek out additional training after their initial teaching and learning center training due to poor experiences. Perhaps programs such as the one discussed by Crede, Borrego, \& McNair ${ }^{13}$ where GTAs are selected for a teaching community of practice are needed to encourage additional training beyond the required initial programs. This may be a way to increase the teaching practice competence of GTAs in engineering.

Aside from formal training, GTAs also mentioned learning teaching practice competence from their instructors or faculty mentors. Often these were informal encounters where faculty would provide insight into a GTAs way of teaching by stopping in their classroom or allowing the GTA to discuss teaching concerns with them after class. These open discussions were salient in terms of learning teaching practice competence to those who discussed them even though they were not formal training sessions. Maurice said:

"There were definitely many.... which all of the TAs had a pretty good relationship with the instructors so there were definitely informal training sessions in the afternoons. If you had a bad day you could just go in and talk and be like, 'I don't know what to do' and they would help talk you through it and figure something out."

These informal training sessions were very valuable to GTAs and were often cited when pedagogy was discussed in the interviews. Corey also said:

"The professors are around sometimes and we do...well, the professors are around and they do walk in occasionally and I do appreciate it. They don't do it really frequently but if they walk in sometimes they will...they just know what we're doing stuff so they'll be able to see what we're doing and they can offer input if they would change something or just advice. But there's no formal training other than that."

Corey found faculty feedback useful and would have liked to have more of it. Seeing faculty as teaching mentors who provide teaching insight aligns with the GTA developmental literature where at the end of the developmental process GTAs are junior colleagues. ${ }^{11}$ In this stage there is a relationship between faculty and GTAs where advice is not just needed, but appreciated and 
welcomed. As engineering education continues to progress forward perhaps building in these GTA-faculty interactions will help strengthen the teaching abilities of our GTAs.

\section{Views of Pedagogy Competence}

With regard to GTAs views of their pedagogy competence, GTAs do feel confident in their abilities and there is an interest in enhancing teaching practice competence. Unfortunately, the mechanisms currently in place for GTAs in FYEPs do not seem to be working to directly support enhanced pedagogical knowledge. In the interviews, participants were directly asked to rate their view of their own general competence (including both content and pedagogical knowledge) on a scale of 1 to 10 where 10 indicated there were an expert in their position regarding needed knowledge. All five of the participants rated themselves between a 6 and 8.5 indicating that overall they feel competent in their role but that there is room for improvement. One of the main areas cited as needing improvement included facilitation in the classroom and facilitation of their role in general. We believe that additional pedagogical training on classroom facilitation in terms of answering student questions and addressing students concerns and overall professional time management could help address this concern relating to pedagogy competence.

Related to interest in pedagogical competence, Ingrid said:

"There came a point where I was interested [in learning pedagogy] and then I was like, I'm going to get through this and then I hit a point where I was like, I'm just going to do the bare minimum I need to do to make sure these students learn and I do my job." Through this quote, we see that some GTAs have an interest in learning pedagogy, but that sometimes their positions do not allow for this additional training because of the other demands that are placed on them. Given that GTAs serve a variety of roles, it makes sense that there would be conflict. Situations like this directly conflict with the notion of training GTAs to be teachers opposed to just being workers presented in past studies. ${ }^{31}$ Ingrid also commented that her position was more of a "course manager" than a teacher. This exemplifies the balance that GTAs must achieve between learning content, learning teaching practices, learning to function within a FYEP in their designated role, and operating effectively in the classroom. The notion of learning to navigate and balance roles and responsibilities has been discussed in previous GTA literature with regard to being a researcher and teacher, ${ }^{32,33}$ but here we see that even within a single role conflict can arise.

\section{Applications of Teaching Practice Knowledge}

Finally with regard to the application of teaching practice competence, GTAs, while they have had little formal training, they do feel confident in their ability to adjust their teaching methods. For example Gordon, a seasoned GTA, said:

"Um, I feel very comfortable towards the end [...] once you get, doing this um, for many years, you can get used to it, you get your own techniques, so sometimes it is a little hard to try and implement newer techniques, when you already have your own process, but you know, you have to be open-minded to listen to other people's ideas and, I, you will always find somebody who will tell you, that they do things in a different way, and they may or may not be more efficient. You might work better until you try it. So you've got to have that mindset." 
This quote demonstrates that change while teaching is difficult because we often get stuck in our ways, but Gordon reminds us that change is needed to enhance education. We often see this in engineering where seasoned faculty may teach as they have always been taught, but reports such as the one by Jamieson and Lohmann ${ }^{10}$ call for a research to practice cycle where teaching practices are directly informed by research and research by teaching. Using this cyclical approach can help break the monotony of teaching, ensuring education is continuously improved opposed to old habits being simply repeated.

In the experiences of our participants, the current teaching practice or pedagogical training of GTAs involved in FYEPs is minimal, but GTAs do have an interest in the topic and receive training from other venues to enhance pedagogy. Also informal mechanisms such as discussions with faculty have an influence on GTAs' teaching practice competence indicating that improving teaching is a general concern in this community.

\section{Limitations}

A limitation of this work is that it only included one individual's perspective from each institution. While appropriate for a qualitative study, having a small sample requires the results to be reviewed critically, understanding that the results of one person may not be indicative of everyone's experience at a particular institution.

Also, the final round of open sub-coding was conducted by only one member of the research team. This individual is well versed in GTA literature and research, but brings an inherent bias to the study because of direct involvement in a FYEP. The researcher addressed her biases through researcher triangulation by discussing findings with individuals both in and out of the first-year engineering community to ensure validity in the findings.

\section{Conclusions}

Currently, GTAs in FYEPs discuss teaching practice competence when they are asked think about training. They often receive training from teaching and learning centers regarding pedagogy and are usually excited and interested in implementing it in their classrooms. Unfortunately, due to the demands that are often placed on GTAs, implementation does not always occur. It is only when a faculty member offers advice that real pedagogical enhancements are implemented. Because of this, we suggest that faculty members and teaching mentors play are more active role in helping GTAs improve their teaching practice competence as they can help with the actual implementation of teaching pedagogy in the demanding role GTAs play. Perhaps additional learning communities and mentoring programs are needed to influence and enhance GTA teaching practice competence.

As the field of engineering education continues to develop, the GTAs, who are, in many cases, future educators and the first face students encounter in their engineering journeys, need to develop competence in the "what" (content) and the "how" (pedagogy) of teaching to ensure future engineers are getting the best education possible. The training they receive to date is making an impact, but more could be done to enhance GTA teaching and the educational experiences of their students. 


\section{Future Work}

Future work for this study will include examining the other components of GTA competence in relation to teaching such as content knowledge and institutional knowledge. It will also include an investigation into the other needs of SDT, autonomy and relatedness, to understand a more holistic picture of GTAs experience. Finally in the future, this research will include a nationwide survey to understand the experiences of GTAs on a more generalized level accounting for both their motivation and identity.

The ultimate goal of this line of research is to understand GTA experiences in engineering from the GTAs' perspective to design programs aimed at fostering the motivation and identity development of GTAs. Our view is that with increased motivation and identity development, we will be preparing better GTAs and future faculty eventually leading to the improvement in the quality of teaching at the undergraduate level.

\section{Acknowledgements}

We would like to thank the GTAs that have participated in this work along with the program directors and coordinators who have given their GTAs the opportunity to be part of our research. As this paper is part of a multi-phased mixed methods study, there have been many ways for GTAs to get involved, and we truly appreciate the ongoing participation and support we have received. Without you, this research would not be possible.

\section{References}

1. Gieskes, K., Bryant, A., \& McGrann, R. (2009). Increasing student-centered learning in a first-year engineering program. Paper presented at the 39th Annual Frontiers in Education Conference, San Antonio, TX.

2. Louis, R. A. \& Matusovich, H. M. (2012). Work-in-progress: Describing the responsibilities of teaching assistants in first-year engineering programs. Paper to be presented at the 42th Annual Frontiers in Education Conference, Seattle, WA.

3. Mullin, J., Lohani, V. K., \& Lo, J. (2006). Work in progress: Teaching a first semester freshman engineering course: A team effort between faculty and graduate teaching assistants at Virginia Tech. Paper presented at the 36th Annual Frontiers in Education Conference, San Diego, CA.

4. Nicklow, J. W., Marikunte, S. S., \& Chevalier, L. R. (2007). Balancing pedagogical and professional practice skills in the training of graduate teaching assistants. Journal of Professional Issues in Engineering Education and Practice, 133(2), 89-94.

5. Ryan, R. M., \& Deci, E. L. (2000). Self-determination theory and the facilitation of intrinsic motivation, social development, and well-being. American Psychologist, 55(1), 68-78. doi: 10.1037/0003-066X.55.1.68

6. La Guardia, J. G. (2009). Developing who I am: A self-determination theory approach to the establishment of healthy identities. Educational Psychologist, 44(2), 90-104. doi: 10.1080/00461520902832350

7. Cho, P., \& Predebon, W. (1996). A teaching assistant training program with a focus on teaching improvement and graduate student development, Paper presented at the 103th American Society for Engineering Education Annual Conference and Exposition, Washington, DC.

8. Csavina, K.R. (2002). The preparing future faculty program at Arizona state university and its role in preparing graduate engineering students for the professoriate. Paper presented at the 109th American Society for Engineering Education Annual Conference and Exposition, Montreal, QB. 
9. Lewandowski, G., \& Purdy C. C. (2001). Training future professors: The preparing future faculty program in electrical and computer engineering and computer science at the university of Cincinnati. Paper presented at the 108th American Society for Engineering Education Annual Conference and Exposition, Albuquerque, NM.

10. Jamieson, L. H., \& Lohmann, J. R. (2009). Creating a culture for scholarly and systematic innovation in engineering education: Ensuring U.S. engineering has the right people with the right talent for a global society. American Society for Engineering Education. Washington, D.C.: American Society for Engineering Education.

11. Nyquist, J. D., \& Sprague, J. (1998). Thinking developmentally about TAs. In M. Marincovich, J. Prostko, \& F. Stout (Eds.), The professional development of graduate teaching assistants, (pp. 61-88). Bolton, MA: Anker.

12. Nyquist, J. D., \& Wulff, D. H. (1996). Preparing teaching assistants for special challenges in teaching. In Working effectively with graduate assistants (pp. 33-45). Thousand Oaks, CA: Sage Publications.

13. Crede, E., Borrego, M., \& McNair, L. D. (2010). Application of community of practice theory to the preparation of engineering graduate students for faculty careers. Advances in Engineering Education, 2(2), 122. Retrieved from http://advances.asee.org/vol02/issue02/papers/aee-vol02-issue02-p04.pdf

14. Cox, M. F., Hahn, J., McNeill, N., Cekic, O., Zhu, J., \& London, J. (2011). Enhancing the quality of engineering graduate teaching assistance through multidimensional feedback. Advances in Engineering Education, 2(3), 1-20. Retrieved from http://advances.asee.org/vol02/issue03/papers/aee-vol02-issue03-p04.pdf

15. Matusovich, H. M., Lee, W. C., Janeski, J. A., \& Winters, K. E. (2011). How instructors and classroom climate contribute to the motivation of first-year engineering students. Paper presented at the 118th American Society for Engineering Education Annual Conference and Exposition, Vancouver, BC.

16. Crede, E., \& Borrego, M. (2009). Preparing graduate engineering students for academia: Assessment of a teaching fellowship. Paper presented at the 116th American Society for Engineering Education Annual Conference and Exposition, Austin, TX.

17. Goodlad, S. ( 1997). Responding to the perceived training needs of graduate teaching assistants. Studies in Higher Education, 22(1), 83-92.

18. Winters, K., \& Matusovich, H. (2011). Graduate teaching assistants' decision making and perceptions of autonomy. Paper presented at the 118th American Society for Engineering Education Annual Conference and Exposition, Vancouver, BC.

19. Harter, S. (1978). Effectance motivation reconsidered: Toward a developmental model. Human Development, 1, 661-669.

20. White, R. W. (1963). Ego and reality in psychoanalytic theory. New York: International Universities Press.

21. Baumeister, R., \& Leary, M. R. (1995). The need to belong: Desire for interpersonal attachments as a fundamental human motivation. Psychological Bulletin, 117, 497-529.

22. Reis, H. T. (1994). Domains of experience: Investigating relationship processes from three perspectives. In R. Erber \& R. Gilmour (Eds.), Theoretical frameworks for personal relationships (pp. 87-110). Hillsdale, NJ: Erlbaum.

23. deCharms, R. (1968). Personal causation. New York: Academic Press.

24. Deci, E. L. (1975). Intrinsic motivation. New York: Plenum.

25. Lim-Teo, S. K., Low, E. L., Wong, A. F., \& Chong, S. (2008). Motivation, competence, and confidence to teach: An exploratory study of the impact of an initial teacher preparation (itp) programme on beginning primary school teachers. KEDI Journal of Educational Policy, 5(2), 41-61.

26. Cubukcu, F. (2010). Student teachers' perceptions of teacher competence and their attributions for success and failure in learning. The Journal of International Social Research, 3(10), 213-217.

27. Mugalogu, E., \& Saribas, D. (2010). Pre-service teachers' competence to design an inquiry based lab lesson. Procedia Social and Behavioral Sciences, 2, 4255-4259.

28. Hollins, E. R. (1993). Assessing teacher competence for diverse populations. Theory into Practice, 32(2), 93 99.

29. Miles, M. B., \& Huberman, A. M. (1994). An expanded sourcebook: Qualitative data analysis. (2nd ed.) Thousand Oaks, CA: Sage Publications.

30. The Boyer Commission on Educating Undergraduates in the Research University. (2001). Reinventing undergraduate education: Three years after the Boyer Report. New York: Stony Brook University: Office of the President. Retrieved from http://dspace.sunyconnect.suny.edu/bitstream/handle/1951/26013/Reinventing\%20Undergraduate\%20Educatio $\mathrm{n} \% 20 \% 28$ Boyer\%20Report $\% 20 \mathrm{II} \% 29$.pdf?sequence $=1$

31. The Boyer Commission on Educating Undergraduates in the Research University. (1998). Reinventing undergraduate education: A blueprint for America's research universities. New York: State University of New York. Retrieved from www.umass.edu/research/system/files/boyer_fromRussell.pdf 
32. Muzaka, V. (2009). The niche of Graduate Teaching Assistants (GTAs): perceptions and reflections. Teaching in Higher Education, 14, 1-12.

33. Louis, R. A. \& McNair, L. D. (2011). Graduate student identity in engineering and education: The creation of an identity construct. Paper presented at the 9th International ePortfolio and Identity Conference, London, UK. 